\title{
Mathematical Modeling of Reactive Extraction of Solute from Slab Solid Material
}

\author{
Indah Hartati ${ }^{1,2}$, Hary Sulistyo ${ }^{1}$, Wahyudi Budi Sediawan ${ }^{1, *}$, \\ Muhammad Mufti Azis ${ }^{1}$, and Moh Fahrurrozi ${ }^{1}$ \\ ${ }^{1}$ Department of Chemical Engineering, Faculty of Engineering, Universitas Gadjah Mada, \\ Jl. Grafika No. 2, Yogyakarta 55281, Indonesia \\ ${ }^{2}$ Department of Chemical Engineering, Faculty of Engineering, Universitas Wahid Hasyim, \\ Jl. Menoreh Tengah X No. 22, Semarang 50236, Central Java, Indonesia
}

${ }^{*}$ Corresponding author:

email:wbsediawan@ugm.ac.id

Received: July 1, 2019

Accepted: August 30, 2019

DOI: $10.22146 /$ ijc. 47181

\begin{abstract}
Reactive extraction is gaining higher attention due its wide application in various solute separation processes. Here, a mathematical model of reactive extraction in slab has been proposed. The model was developed by considering simultaneous processes of active compound intra particle diffusion, second order elemental reaction of soluteactive compound, and intra-particle product diffusion. The obtained partial differential equations (PDEs) were solved using Finite Difference Approximation (FDA) method by using realistic parameters. Concentration profile as well as product yield were evaluated as a function of time. As a result, the model proposed here may serve as a basis design for reactive extraction unit. Sensitivity analyses was conducted to inspect the influence of slab thickness, diffusivity and reaction rate constant to the product yield. Eventually, model validation was conducted by comparing the simulation results with analytical solutions for special cases. Validation results showed that the model gave good agreement with the analytical solution.
\end{abstract}

Keywords: mathematical modeling; reactive extraction; separation; slab; simulation

\section{- INTRODUCTION}

In recent years, reactive extraction has been shown as an attractive and promising technique for separation of various valuable solutes and for synthesis of various products. Its attractiveness is due to the combination of physical and chemical processes which may enhance the extraction yield of valuable solutes and products [1]. The combination of two processes leads to a higher solute distribution coefficient, a higher extraction efficiency, and allowing transport processes intensification by increasing mass transfer and chemical reactions rates [1-2]. Reactive extraction is also prized for its simplicity, technical accessibility, novelty, moderate conditions and possibility of utilization of green, cheap and efficient chemicals [3-4].

Reactive extraction has been studied and applied in various systems, either in liquid-liquid system [4], solidfluid system [5] and gas-liquid-liquid system [6]. In practical terms, reactive extraction is commercially applied in separation of metals [7-8], separation of intermediates [9-10], separation of organic acids [1112], separation of vitamins [13], separation of lignin [1416], synthesis of biodiesel [17] and preparation of green oxidants such as hydrogen peroxide [6].

There have been numerous extensive fundamental studies focused on process optimization, kinetics, equilibrium and modeling of liquid-liquid reactive extraction processes[18-20]. Meanwhile, Lu et al. [6] investigated the kinetics aspects of gas-liquid-liquid reactive extraction process for hydrogen peroxide production. Moreover, in the case of solid-liquid reactive extraction processes, available literature that mainly focus on the development of a mathematical model for solid liquid reactive extraction is still limited. Hence, the aim of this paper was to develop a mathematical model of solid liquid reactive extraction to extract valuable solute from a slab solid material. 


\section{- MODELING METHOD}

By using chemical engineering principles, a mathematical model could be developed to improve scientific understanding related to the reactive extraction system behavior and to support the design of reactive extraction system for commercial purposes.

\section{Model Development}

The mathematical model of reactive extraction of solute from a slab material was developed based on mass balance equations, rate process and equilibrium concepts. The model was constructed by applying the following mechanisms and assumptions:

(i) The solid-liquid extraction of solute from slab material consists of the following consecutive steps:

(a) $\mathrm{A}_{\text {(bulk liquid) }} \rightarrow \mathrm{A}_{\text {(surface) }}$ : the active compound (A) is transferred from the bulk of liquid to the solid surface

(b) $\mathrm{A}_{\text {(surface) }} \rightarrow \mathrm{A}_{\text {(interior): }}$ : the active compound in solid surface diffuses to the inner part of the solid particle

(c) $\mathrm{A}+\mathrm{B} \rightarrow \mathrm{C}$ : the active compound reacts with the targeted solute $\mathrm{B}$ producing a soluble product $\mathrm{C}$

(d) $\mathrm{C}_{\text {(interior) }} \rightarrow \mathrm{C}_{\text {(surface) }}$ : the product $\mathrm{C}$ diffuses from the interior part to the solid surface

(e) $\mathrm{C}_{\text {(surface) }} \rightarrow \mathrm{C}_{\text {(bulk liquid) }}$ : the product $\mathrm{C}$ is transferred to the bulk of the liquid.

The concentration profile of $\mathrm{A}, \mathrm{B}$ and $\mathrm{C}$ can be schematically illustrated as shown in Fig. 1.

(ii) Step (a) and (e) are fast enough, so they do not control the overall rate of the process and the solute concentrations in the liquid in contact with the slab

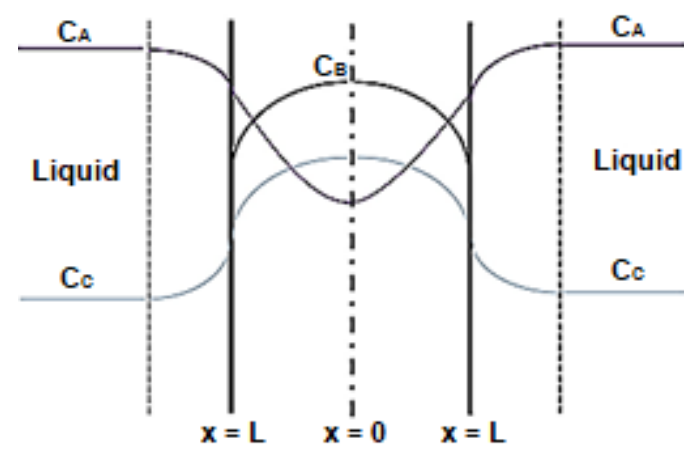

Fig 1. Schematic diagram of the concentration profile of the active compound (A), solute (B) and product (C) surface and the one in the bulk are equal.

(iii) Diffusion of the active compound (A) and of the soluble product $(\mathrm{C})$ in the solid particle follows Fick's type equation: $\mathrm{N}_{\mathrm{A}}=-\mathrm{D}_{\mathrm{eA}} \cdot \frac{\partial \mathrm{C}_{\mathrm{A}}}{\partial \mathrm{x}}$ and $\mathrm{N}_{\mathrm{C}}=-\mathrm{D}_{\mathrm{eC}} \cdot \frac{\partial \mathrm{C}_{\mathrm{C}}}{\partial \mathrm{x}}$, respectively

(iv) The rate of chemical reaction can be approximated by an elemental kinetics: $-\mathrm{rA}=-\mathrm{rB}=\mathrm{rC}=\mathrm{k}_{\mathrm{r}} \cdot \mathrm{C}_{\mathrm{A}} \cdot \mathrm{C}_{\mathrm{B}}$

(v) The unreacted solute, $\mathrm{B}$, is immobile in the solid.

The volume element in one dimensional simultaneous diffusion and chemical reaction simplified as shown in Fig. 2.

The unsteady state mole balance in axial direction of the active compound (A) in the solid volume element with the thickness of $\Delta \mathrm{x}$ and cross section area of $\mathrm{S}$ can be written as:

Rate of mass input - Rate of mass output $=$ Rate of mass accumulation

$\left(-\left.D_{e A} \cdot S \cdot \frac{\partial C_{A}}{\partial x}\right|_{x}\right)-\left(-\left.D_{e A} \cdot S \cdot \frac{\partial C_{A}}{\partial x}\right|_{x+\Delta x}\right)-S \cdot \Delta x \cdot k_{r} \cdot C_{A} C_{B}$

$=\mathrm{S} \cdot \Delta \mathrm{x} \cdot \varepsilon \cdot \frac{\partial \mathrm{C}_{\mathrm{A}}}{\partial \mathrm{t}}$

In this case, the advection term is to be neglected because inside the particle, the liquid is practically stationary. After algebraic arrangement, it is obtained:

$\lim _{\Delta x \rightarrow 0} D_{e A} \frac{\left.\frac{\partial C_{A}}{\partial x}\right|_{x+\Delta x}-\left.\frac{\partial C_{A}}{\partial x}\right|_{x}}{\Delta x}-k_{r} C_{A} C_{B}=\varepsilon \frac{\partial C_{A}}{\partial t}$

If $\Delta \mathrm{x}$ is taken to be infinitely small, the following differential equation is formed:

$\frac{\partial^{2} \mathrm{C}_{\mathrm{A}}}{\partial \mathrm{x}^{2}}-\frac{\mathrm{k}_{\mathrm{r}} \cdot \mathrm{C}_{\mathrm{A}} \mathrm{C}_{\mathrm{B}}}{\mathrm{D}_{\mathrm{eA}}}=\frac{\varepsilon}{\mathrm{D}_{\mathrm{eA}}} \frac{\partial \mathrm{C}_{\mathrm{A}}}{\partial \mathrm{t}}$

The mole balance of solute (B) in solid volume element was developed by assuming that the solute reacted

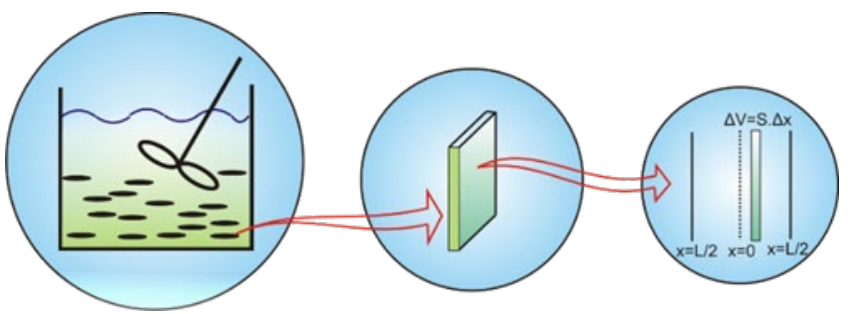

Fig 2. Schematic diagram of reactive extraction modeling in various scales 
with the active compound (A) and produces a soluble product $(\mathrm{C})$. In addition, the remaining solute is immobile thus the mass balance was arranged without considering the diffusion of $B$ in the slab. Derivation of mass balance of $B$ gives:

$\frac{\partial \mathrm{C}_{\mathrm{B}}}{\partial \mathrm{t}}=-\frac{\mathrm{k}_{\mathrm{r}} \cdot \mathrm{C}_{\mathrm{A}} \mathrm{C}_{\mathrm{B}}}{\varepsilon}$

Construction of mole balance of product $\mathrm{C}$ was based on simultaneous internal diffusion and reaction in the solid. Similar to the mole balance of $\mathrm{A}$, the mass balance for component $\mathrm{C}$ results in:

$\frac{\partial^{2} \mathrm{C}_{\mathrm{C}}}{\partial \mathrm{x}^{2}}+\frac{\mathrm{k}_{\mathrm{r}} \cdot \mathrm{C}_{\mathrm{A}} \mathrm{C}_{\mathrm{B}}}{\mathrm{D}_{\mathrm{eC}}}=\frac{\varepsilon}{\mathrm{D}_{\mathrm{eC}}} \frac{\partial \mathrm{C}_{\mathrm{C}}}{\partial \mathrm{t}}$

The initial conditions for Eq. (3-5) are:

$\mathrm{C}_{\mathrm{A}}(\mathrm{t}=0, \mathrm{x})=0 ; \mathrm{C}_{\mathrm{B}}(\mathrm{t}=0, \mathrm{x})=\mathrm{C}_{\mathrm{B} 0} ; \mathrm{C}_{\mathrm{C}}(\mathrm{t}=0, \mathrm{x})=0$

The boundary conditions for Eq. (3-5), in which comprised of the boundary conditions at the outer surface of the slab (Eq. (7)) and the ones at the center of the slab (Eq. (8)) are:

$\mathrm{C}_{\mathrm{A}}(\mathrm{t}, \mathrm{x}= \pm \mathrm{L} / 2)=\mathrm{C}_{\mathrm{Af}} ; \mathrm{C}_{\mathrm{C}}(\mathrm{t}, \mathrm{x}= \pm \mathrm{L} / 2)=\mathrm{C}_{\mathrm{Cf}}$

$\frac{\partial \mathrm{C}_{\mathrm{A}}}{\partial \mathrm{x}}(\mathrm{t}, \mathrm{x}=0)=0 ; \frac{\partial \mathrm{C}_{\mathrm{B}}}{\partial \mathrm{x}}(\mathrm{t}, \mathrm{x}=0)=0 ; \frac{\partial \mathrm{C}_{\mathrm{c}}}{\partial \mathrm{x}}(\mathrm{t}, \mathrm{x}=0)=0$

The mass balance of $\mathrm{A}$ in the liquid phase produces:

$\frac{\partial \mathrm{C}_{\mathrm{Af}}}{\partial \mathrm{t}}=-\left.\frac{\mathrm{D}_{\mathrm{eA}}}{\mathrm{V}_{\mathrm{L}}} \cdot 2 \mathrm{~S} \cdot \mathrm{Nb} \cdot \frac{\partial \mathrm{C}_{\mathrm{A}}}{\partial \mathrm{x}}\right|_{\mathrm{L} / 2}$

Similarly, it is obtained by the mass balance of component C that:

$\frac{\partial \mathrm{C}_{\mathrm{Cf}}}{\partial \mathrm{t}}=-\left.\frac{\mathrm{D}_{\mathrm{eC}}}{\mathrm{V}_{\mathrm{L}}} \cdot 2 \mathrm{~S} \cdot \mathrm{Nb} \cdot \frac{\partial \mathrm{C}_{\mathrm{C}}}{\partial \mathrm{x}}\right|_{\mathrm{L} / 2}$

Eq. (9-10) were solved based on the following initial conditions:

$\mathrm{C}_{\mathrm{A}}(\mathrm{t}=0)=\mathrm{C}_{\mathrm{A} 0} ; \mathrm{C}_{\mathrm{C}}(\mathrm{t}=0)=0$

\section{Simulation Method: Finite Difference Approximation and Method of Lines}

The set of equations which represents the reactive extraction system was numerically solved using the FDA method. Due to the symmetrical system, Eq. (3-5) were solved only from $\mathrm{x}=0$ (at the center of the slab) to $\mathrm{x}=\mathrm{L} / 2$ at the outer surface of the slab. For FDA computation, central finite difference approach was used to discretize the first and second order differential equation in axial direction. The results were displayed in a surface plot with color map showing the concentration in axial position and time.

\section{Evaluation of the Conversion of $B\left(X_{B}\right)$ and Yield of $C$}

The concentration profile of $B$ in the slab interior facilitates the evaluation of the conversion of $\mathrm{B}$ as a function of time. The overall conversion of $B\left(X_{B}\right)$ was evaluated via integration of the total mass of $B$ remaining in the solid. Similarly, the extraction yield of product $\mathrm{C}$ can also be computed as the ratio of the amount of $\mathrm{C}$ released into the liquid and the initial amount of $B$ in the slab.

\section{- RESULTS AND DISCUSSION}

\section{Simulation Result of Base Case}

One example of solid-liquid reactive extraction system is the separation of lignin from various biomass using sulfuric acid as the active compound. Hence, the proposed model was constructed and simulated by assuming that sulfuric acid acted as the active compound (A), lignin as the solute (B) and soluble lignin product as the reactive extraction product $(\mathrm{C})$. In the case of lignin separation from lignocellulosic biomass, lignin is strongly bonded to the other two components that exist in the biomass, namely cellulose and hemicellulose, thus the unreacted lignin was assumed to be immobile.

The parameters for base case simulation of reactive extraction mathematical model are tabulated in Table 1 , and the background for the parameters value set for the simulation are presented in this section. The dimension parameters of the slab material applied for the base case simulation were based on the dimension of the lignocellulose material, i.e. sugarcane bagasse, which is frequently utilized as raw material for the reactive

Table 1. Parameters for base case simulation of reactive extraction mathematical model

\begin{tabular}{llll}
\hline Parameter & Unit & Parameter & Unit \\
\hline $\mathrm{L}=0.4$ & $\mathrm{~cm}$ & $\mathrm{D}_{\mathrm{eC}}=1.10^{-4}$ & $\mathrm{~cm}^{2} / \mathrm{min}$ \\
$\mathrm{nx}=20$ & - & $\mathrm{D}_{\mathrm{eA}}=2.10^{-4}$ & $\mathrm{~cm}^{2} / \mathrm{min}$ \\
$\mathrm{dx}=\mathrm{L} /(2 . \mathrm{nx})$ & $\mathrm{Cm}$ & $\mathrm{k}_{\mathrm{r}}=2.10^{-1}$ & $\mathrm{~cm}^{3} /(\mathrm{mol} . \mathrm{min})$ \\
$\mathrm{S}=4$ & $\mathrm{~cm}^{2}$ & $\mathrm{C}_{\mathrm{A} 0}=0.1$ & $\mathrm{~mol} / \mathrm{cm}^{3}$ \\
$\mathrm{~V}_{\mathrm{L}}=1.10^{3}$ & $\mathrm{~cm}^{3}$ & $\mathrm{C}_{\mathrm{B} 0}=0.2$ & $\mathrm{~mol} / \mathrm{cm}^{3}$ \\
$\mathrm{~N}_{\mathrm{b}}=1.10^{2}$ & - & $\varepsilon=0.4$ & - \\
\hline
\end{tabular}


extraction of lignin. Zhao et al. [21] stated that lignocellulose generally denotes to the secondary cell wall tissue of plants and that the shape of the sugarcane bagasse cell is simplified as a 3D cuboid with a slab shape cell wall. Sugarcane bagasse fiber length is reported to vary from 120 to $160 \mu \mathrm{m}$ [22-23]. The thickness of the slab material in this simulation was set to $4 \mathrm{~mm}$ and the cross sectional area of the slab, perpendicular to the $\mathrm{x}$-axis $\left(\mathrm{cm}^{2}\right)$, was $4 \mathrm{~cm}^{2}$. The length of the slab was assumed to be equal to the width of the slab, hence the length of the slab was $2 \mathrm{~cm}$. It is logical since the milling process usually produces bigger and longer dimensions of biomass compared to the fiber dimension. The aspect ratio (AR), which is defined as the dimensionless ratio between the length and the thickness of the particle [24], was 5. This is also a realistic assumption since according to particle classification based on its shape factors, particles are classified into several classes, in which one of the classes is rectangle fibrous which has AR higher than 3.3 [24]. The effective diffusivity of the active compound $\left(D_{e A}\right)$ and the soluble product of reactive extraction $\left(\mathrm{D}_{\mathrm{eC}}\right)$ used in the base case simulation were $2.10^{-4} \mathrm{~cm}^{2} / \mathrm{min}$ and $1.10^{-4} \mathrm{~cm}^{2} / \mathrm{min}$, respectively. The effective diffusivity of the active compound value taken in this simulation was reasonable since it was smaller than the molecular diffusivity of the active compound in the liquid system commonly utilized in the reactive extraction [21]. In the case of lignin separation, sulphuric acid is one of the commercially active compounds commonly used in the reactive extraction of lignin. Since Pirogov et al. [25] mentioned that the effective diffusivity of sulphuric acid in aqueous solution is $2.04 \times 10^{-2} \mathrm{~cm}^{2} / \mathrm{min}$ and Zhao et al. [21] stated that the effective diffusivity of chemical compounds in solid systems are smaller than the one in the liquid system, then for this simulation, the effective diffusivity of the active compound $\mathrm{D}_{\mathrm{eA}}$ which was set smaller than the effective diffusivity of sulphuric acid in aqueous system was realistic. Moreover, the effective diffusivity of the soluble product, $\mathrm{D}_{\mathrm{eC}}$, was set smaller than the effective diffusivity of the active compound. Li et al. [26] found that diffusivity of linear and globular molecules decrease with increasing molecular weight, in which the linear molecules decreasing rate is faster than the one of the globular molecules. In the case of the reactive extraction of lignin, the soluble product has high molecular weight and larger size than the active compound such as sulphuric acid. Lignin is reported to have molecular weight ranging from $2,330-21,500 \mathrm{~g} \mathrm{~mol}^{-1}$ depending on the biomass sources and the separation processes applied [27], while molecular weight of sulphuric acid is $98.08 \mathrm{~g} \mathrm{~mol}^{-1}$. Furthermore, the reaction rate constant for the simulation of the reactive extraction of lignin using sulphuric acid as the active compound was set to $2 \times 10^{-1} \mathrm{~cm}^{3} /(\mathrm{mol}-\mathrm{min})$, six orders of magnitudes bigger than the reaction rate constant for lignin extraction reported by Zhao et al. in [21] which utilized acetic acid for the reactive extraction of lignin. It was reported that the reaction rate constant in the early stage of sugarcane bagasse lignin reactive extraction in acetic acid medium ranged from $2.64 \times 10^{-6}-2.46 \times 10^{-7}$ $\mathrm{cm}^{3} /$ (mol.min) for reactive extraction conducted at temperatures that ranged from $90{ }^{\circ} \mathrm{C}-100{ }^{\circ} \mathrm{C}$ and acetic acid concentration ranging from $70 \%-90 \%$ [21]. The high reaction rate constant applied in this work was logical since sulphuric acid is stronger than acetic acid.

The simulation results for the base case presented in Fig. 3 shows the color maps concentration of A, B, C as a function of the axial position ( $\mathrm{x}$-axis) and extraction time ( $y$-axis). It should be noted that $x=0$ and 0.2 denoted the center and the surface of the slab, respectively. Fig. 3(a) shows penetration of the active compound A from the exterior to the interior part of the slab along with extraction time. The presence of $\mathrm{A}$ in the slab caused reaction with solute $B$. As a result, the amount of $B$ in the slab was depleted (Fig. 3(b)). In addition, the production of $\mathrm{C}$ can be seen clearly occurring simultaneously which showed 'hot spots' of concentration of $\mathrm{C}$ at the center of the slab within the interval of 50-150 min (Fig. 3(c)). With the increase of extraction time, product $\mathrm{C}$ would gradually release to the bulk liquid and cause the removal of compound $\mathrm{C}$ from the slab.

\section{Evaluation of Conversion of $B\left(X_{B}\right)$ and Yield $C$}

Fig. 4 displays the results of $\mathrm{X}_{\mathrm{B}}$ and Yield $\mathrm{C}$ as a function of time. As seen here, both $\mathrm{X}_{\mathrm{B}}$ and Yield $\mathrm{C}$ increased with extraction time. However, the increase of $\mathrm{X}_{\mathrm{B}}$ was faster than the Yield C. The slow increase of Yield C 

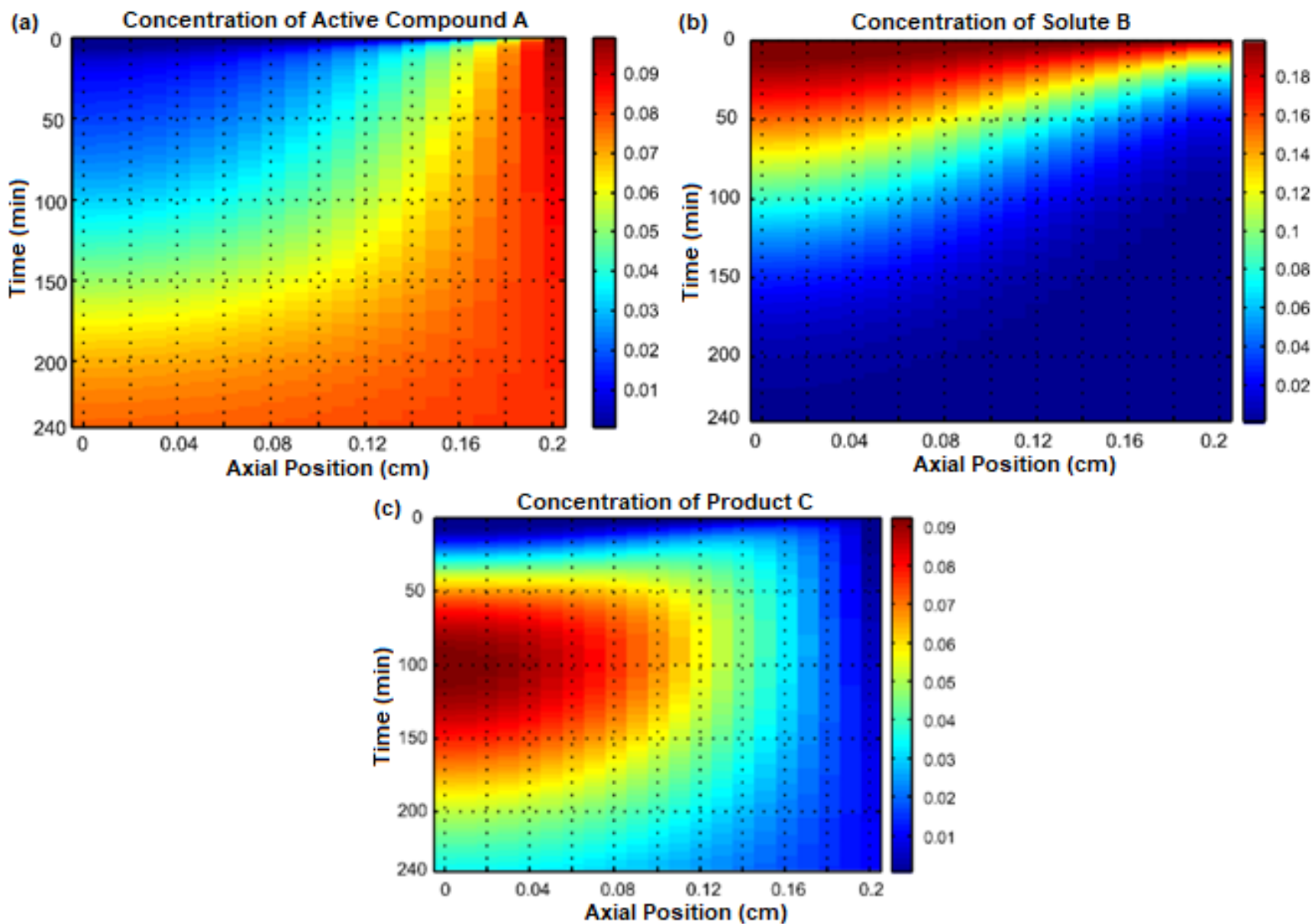

Fig 3. Concentration profile of A (a), B (b), C (c) in the slab interior as a function of time and position

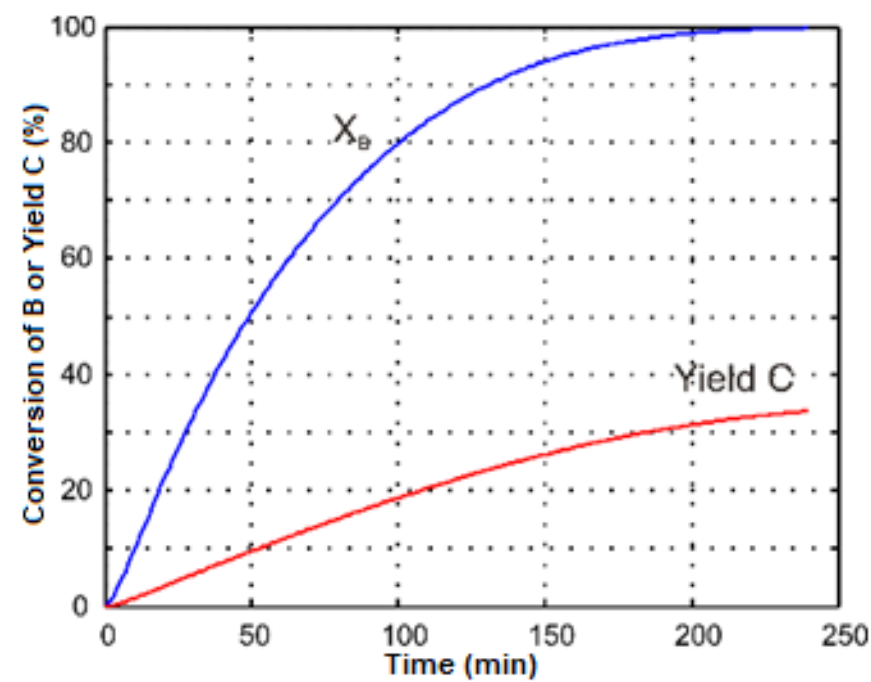

Fig 4. The evolution of $X_{B}$ and Yield $C$ as a function of extraction time

was conceivable due to internal mass transport resistance for product $\mathrm{C}$ in the slab. The effective diffusivity of the soluble product was smaller than the one of the active compound, hence some of the soluble products produced were entrapped in the pores of the slab particle and resulted in the slower rate of the increase of Yield $\mathrm{C}$ than the increase of $\mathrm{X}_{\mathrm{B}}$. Conversion of $\mathrm{B}$ as high as $99 \%$ was achieved at $207 \mathrm{~min}$ while the highest Yield of $\mathrm{C}$ was $33.7 \%$ at the end of $240 \mathrm{~min}$.

\section{Sensitivity Analyses}

Sensitivity analyses, one of the essential aspect in good modeling practice, were performed to investigate how variations in the observable outcome of the mathematical model proposed can be attributed to variations in its input factors [28]. The sensitivity analysis was conducted to study the influence of slab thickness, effective diffusivity of $\mathrm{A}$ and the reaction rate constant to the yield of $\mathrm{C}$ in the liquid phase. The influence of each parameter was evaluated by systematically changing their 

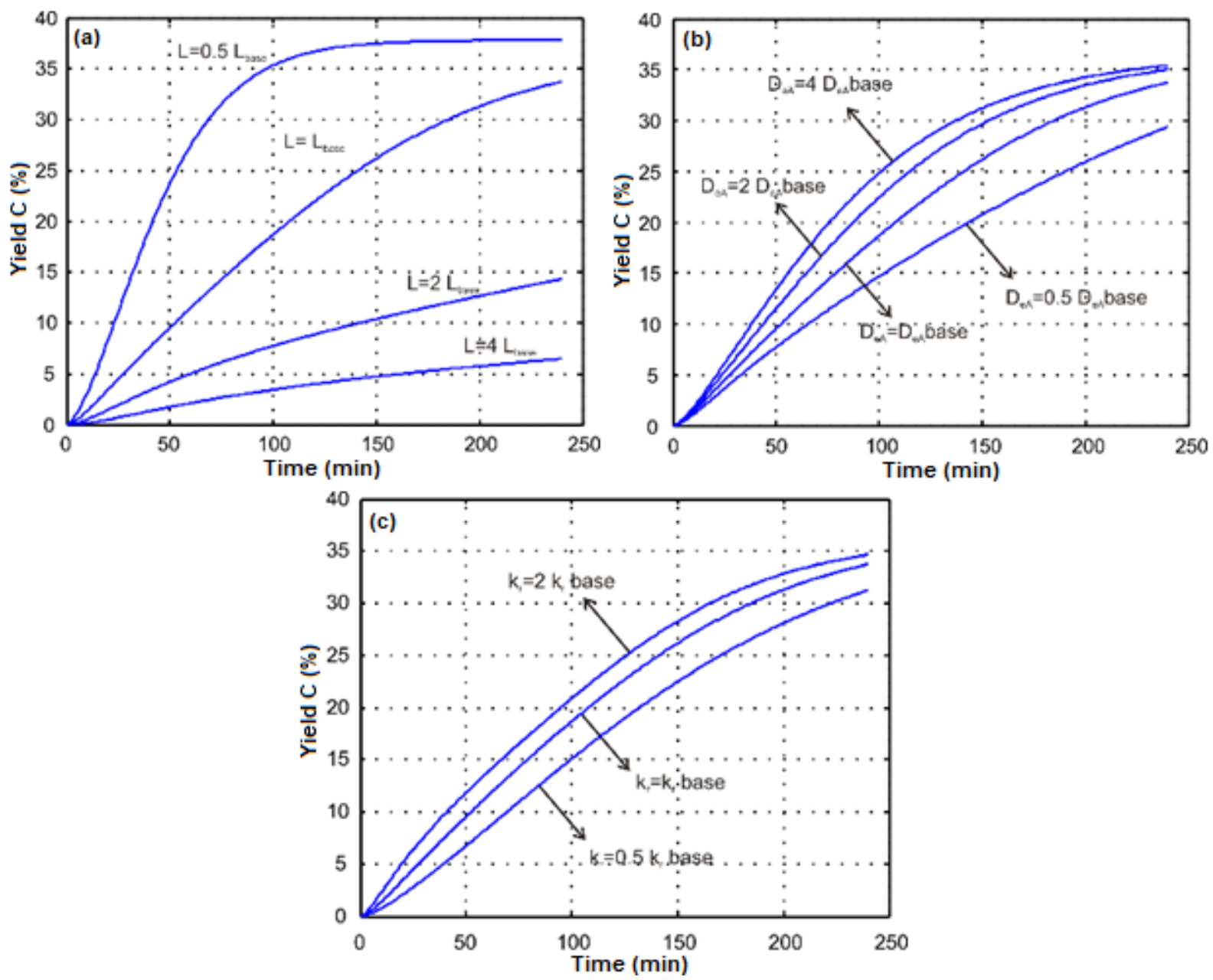

Fig 5. The influence of slab thickness (a), $D_{e A}(b)$ and $k_{r}(c)$ to the yield of $C$ in the liquid phase

values using one of the local sensitivity analysis, One Factor at a Time (OFAT) method.

Fig. 5(a) shows the influence of slab thickness to the Yield C. As seen here, reducing the slab half from the base case would give an increase of Yield. On the contrary, a thicker slab would give lower yield. This is conceivable as the thicker the slab the higher the internal mass transfer resistance in the slab. The influence of $\mathrm{D}_{\mathrm{eA}}$ was evaluated (Fig. 5(b)) to the yield of C. It appeared that higher $D_{\mathrm{eA}}$ gave higher Yield. However, increasing the $\mathrm{D}_{\mathrm{eA}}$ from $2 \mathrm{D}_{\mathrm{eA}}$ base to $4 \mathrm{D}_{\mathrm{eA}}$ base gave marginal increase of the Yield. It could be inferred that when $\mathrm{D}_{\mathrm{eA}}$ is high, the Thiele Module, a measure for the ratio of the reaction rate to the rate of diffusion, would be smaller [29]. Fogler [30] and Sulaiman et al. [17] mentioned that the small value of the Thiele Module indicates that the chemical reaction is rate-limiting, and as a result, the Yield of $\mathrm{C}$ would largely be controlled by the chemical reaction. Sensitivity of Yield to the reaction rate constant $\left(k_{\mathrm{r}}\right)$ is shown in Fig. 5(c). It is logical that increasing the $\mathrm{k}_{\mathrm{r}}$ would give higher reaction rate and thus an increase of Yield $\mathrm{C}$ which was confirmed by the model.

\section{Model Validation}

The validation of the model was conducted by comparing the results of the proposed model to the analytical solution for special cases in which their analytical solutions are available.

\section{Scenario 1: The case of very slow reaction and} constant active compound concentration in the liquid

In the case of very slow reaction and constant active compound concentration in the liquid (by setting the volume of the liquid to be very large), the model proposed would exhibit similar phenomena as in the 
pure absorption in a slab in which its analytical solution is widely available from literature. The differential equation of pure absorption is:

$\frac{\partial^{2} \mathrm{C}_{\mathrm{A}}}{\partial \mathrm{x}^{2}}=\frac{\varepsilon}{\mathrm{D}_{\mathrm{eA}}} \frac{\partial \mathrm{C}_{\mathrm{A}}}{\partial \mathrm{t}}$

The initial condition and the boundary conditions of the problem are:

$\mathrm{C}_{\mathrm{A}}=0$ for $\mathrm{t}=0$ at all $\mathrm{x}$

$\mathrm{C}_{\mathrm{A}}=\mathrm{C}_{\mathrm{A} 0}$, at $\mathrm{x}=\mathrm{L}$, all $\mathrm{t}$

$\frac{\partial \mathrm{C}_{\mathrm{A}}}{\partial \mathrm{x}}=0$, at $\mathrm{x}=0$, all $\mathrm{t}$

$\mathrm{C}_{\mathrm{A}}=\mathrm{C}_{\mathrm{Af}}$, at $\mathrm{t}=\infty$, all $\mathrm{x}$

Solution method for Eq. (12) with the initial and boundary conditions of Eq.(13) and Eq. (14a-c) was found in a previous research [31], and the solution is as follows:

$\mathrm{C}_{\mathrm{A}, \text { ana }}=\mathrm{C}_{\mathrm{Af} 0}\left[1-\frac{4}{\pi} \sum_{\mathrm{n}=0} \frac{(-1)^{\mathrm{n}}}{2 \mathrm{n}+1} \cos \left(\frac{(2 \mathrm{n}+1) \pi \mathrm{x}}{2 \mathrm{~L}}\right) \exp \left(-\frac{(2 \mathrm{n}+1)^{2}(\pi)^{2} \mathrm{D}_{\mathrm{eA}} \mathrm{t}}{4 \varepsilon \mathrm{L}^{2}}\right)\right]$

For simulations of the pure absorption of $\mathrm{A}$, we set a number of parameters as follows: half slab thickness of $0.4 \mathrm{~cm}$, diffusivity of active compound in the solid particle $\left(D_{e A}\right)$ of $2.10^{-4} \mathrm{~cm}^{2} / \mathrm{min}$, reaction rate constant of $1.10^{-6}$ $\mathrm{cm}^{3} / \mathrm{min}$-mol, time of extraction of $30 \mathrm{~min}$ by keeping other parameters the same as in the base case. The comparison of the numerical simulation using the reactive extraction model and the analytical solutions are presented in Fig. 6. It is clear that the model results are very close to the analytical solutions. This result shows that the model proposed for this special case is consistent.

\section{Scenario 2: The case of very slow diffusivity or thick slab}

For very thick slab or very slow diffusivity in the solid slab, which occurs at relatively short time, the penetration of the active compound will be limited to the vicinity of the slab surface. The analytical solution for this case is also available. The differential equation is similar to Eq. (12). Meanwhile the initial and boundary conditions are:

$\mathrm{C}_{\mathrm{A}}=0$ for $\mathrm{t}=0$ at $\mathrm{x}$

$\mathrm{C}_{\mathrm{A}}=\mathrm{C}_{\mathrm{Af}}$ at $\mathrm{x}=0$ all $\mathrm{t} ; \mathrm{C}_{\mathrm{A}}=0$ at $\mathrm{x}=\infty$ all $\mathrm{t}$

in which $\mathrm{x}$ is the distance from the surface of the slab. The solution of Eq. (12) with boundary conditions of Eq. (16-17) is as follows [32]:

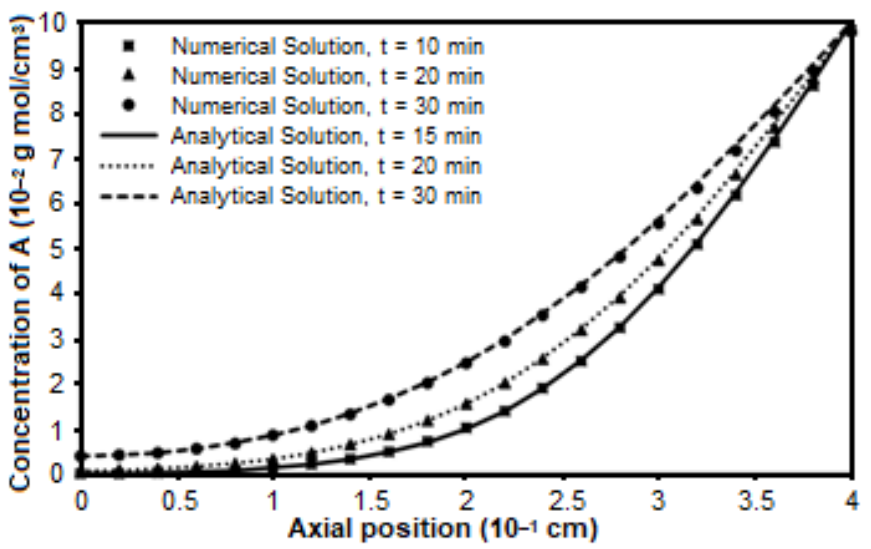

Fig 6. Comparison of analytical solutions and the ones from the model proposed for very slow reaction

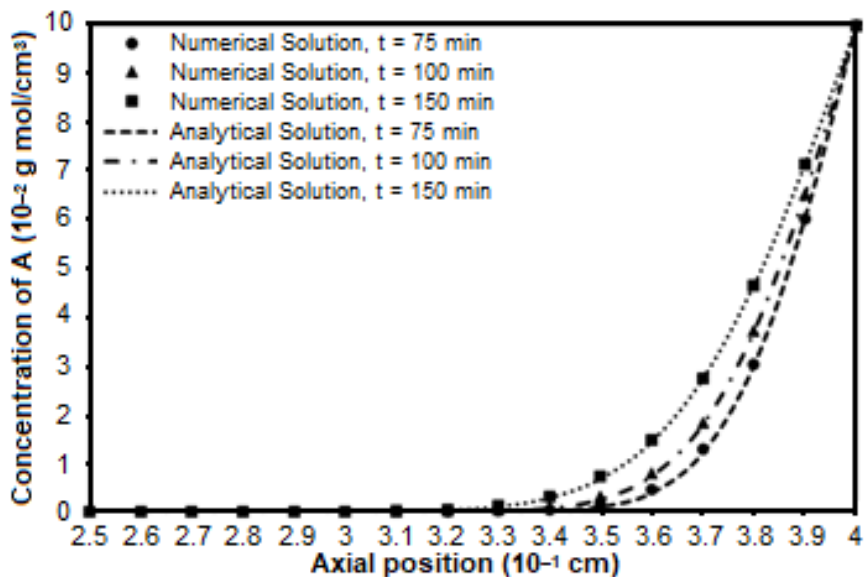

Fig 7. Comparison of analytical solutions and the ones from the model proposed for very slow diffusion and no reaction

$\mathrm{C}_{\mathrm{A}, \text { anal }}=\mathrm{C}_{\mathrm{Af0}}\left[1-\operatorname{erf}\left(\frac{\mathrm{x} \sqrt{\varepsilon}}{\sqrt{4 \mathrm{D}_{\mathrm{eA}} \mathrm{t}}}\right)\right]$

Fig. 6 illustrates the comparison of the numerical simulation using the reactive extraction model and the analytical solutions for the simulations of short penetration of the active compound from the liquid to slab with half slab thickness of $0.4 \mathrm{~cm}$, diffusivity of active compound in the solid particle $\left(\mathrm{D}_{\mathrm{eA}}\right)$ of $1.10^{-6} \mathrm{~cm}^{2} / \mathrm{min}$, reaction rate constant of $1.10^{-6} \mathrm{~cm}^{3} / \mathrm{min} / \mathrm{mol}$, time of extraction of $150 \mathrm{~min}$, and the other model parameters were in accordance to the base case. The comparison of the results is presented in Fig. 7. It can be observed that the model results are very close to the analytical solutions. Hence, the consistency of the model is again confirmed. 


\section{- CONCLUSION}

Modeling of reactive extraction in a slab was presented in this study. Simultaneous PDEs were solved with the FDA method by using realistic parameters. The simulation results gave a concentration profile as well as product yield as a function of extraction time. It is expected that the model may give better understanding on the mechanism of reactive extraction and it may serve as a basis design for reactive extraction unit as well. Sensitivity analyses were conducted to inspect the influence of slab thickness, diffusivity and reaction rate constant to the product yield. Model validation was conducted by comparing numerical and analytical solutions for simple cases. The validation shows that the results of the proposed model are in good agreement with the analytical solutions for special cases.

\section{- ACKNOWLEDGMENTS}

This work is supported by the Ministry of Research, Technology and Higher Education of Republic of Indonesia through PDUPT research grant of 2018, contract number of 118/UN1/DITLIT/DIT-LIT/LT/2018.

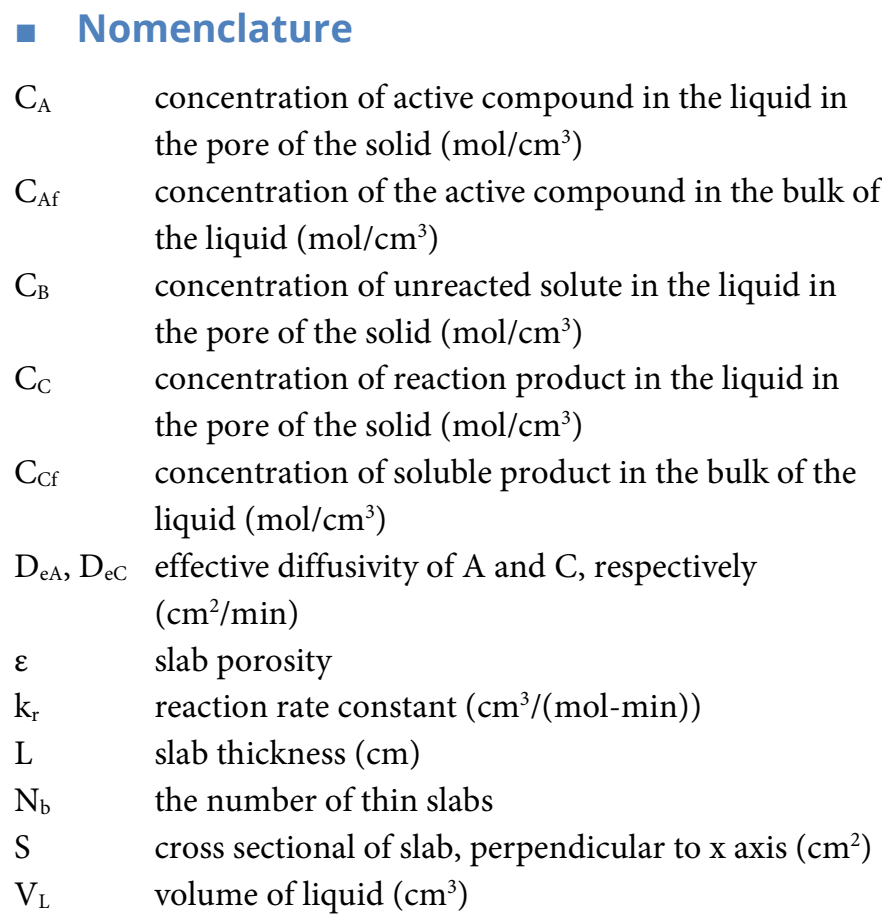

\section{- REFERENCES}

[1] Sharma, S., Agarwal, G.K., and Dutta, N.N., 2019, LSER analysis of reactive extraction of $\mathrm{Zn}$ and $\mathrm{Cu}$ with bis (2-ethylhexyl) phosphate (HDEHP) in six different diluents, Sep. Sci. Technol., 54 (7), 11671173.

[2] Zeng, Q., Qin, H., Cheng, H., Chen, L., and Qi, Z., 2019, Development of a reactive extraction process for isobutyl isobutyrate formation intensified by bifunctional ionic liquid, Chem. Eng. Sci. X, 1, 100001.

[3] Pradhan, S., Madankar, C.S., Mohanty, P., and Naik, S.N., 2012, Optimization of reactive extraction of castor seed to produce biodiesel using response surface methodology, Fuel, 97, 848-855.

[4] Santoso, I., Buchari, Amran, M.B., and Sulaeman, A., 2007, The effect of concentration of carrier, $\mathrm{pH}$ and time of extraction on separation's factor of penicillin G-phenyl acetate by reactive extraction, Indones. J. Chem., 7 (2), 185-189.

[5] Tuntiwiwattanapun, N., and Tongcumpou, C., 2018, Sequential extraction and reactive extraction processing of spent coffee grounds: An alternative approach for pretreatment of biodiesel feedstocks and biodiesel production, Ind. Crops Prod., 117, 359-365.

[6] Lu, S., Wang, L., Wang, Y., and Mi, Z., 2011, Kinetic model of gas-liquid-liquid reactive extraction for production of hydrogen peroxide, Chem. Eng. Technol., 34 (5), 823-830.

[7] Chemarin, F., Moussa, M., Chadni, M., Pollet, B., Lieben, P., Allais, F., Trelea, I.C., and Athès, V., 2017, New insights in reactive extraction mechanisms of organic acids: An experimental approach for 3-hydroxypropionic acid extraction with tri- $n$-octylamine, Sep. Purif. Technol., 179, 523-532.

[8] Lu, X., Zhang, D., He, S., Feng, J., Reda, A.T., Liu, C., Yang, Z., Shi, L., and Li, J., 2017, Reactive extraction of europium(III) and neodymium(III) 
by carboxylic acid modified calixarene derivatives: Equilibrium, thermodynamics and kinetics, Sep. Purif. Technol., 188, 250-259.

[9] Gorden, J., Zeiner, T., and Brandenbusch, C., 2015, Reactive extraction of cis,cis-muconic acid, Fluid Phase Equilib., 393, 78-84.

[10] Waghmare, M.D., Wasewar, K.L., Sonawane, S.S., and Shende, D.Z., 2013, Reactive extraction of picolinic and nicotinic acid by natural non-toxic solvent, Sep. Purif. Technol., 120, 296-303.

[11] Tang, K., Miao, J., Zhou, T., and Liu, Y., 2011, Equilibrium studies on liquid-liquid reactive extraction of phenylsuccinic acid enantiomers using hydrophilic $\beta$-CD derivatives extractants, Chin. J. Chem. Eng., 19 (3), 397-403.

[12] Chemarin, F., Moussa, M., Allais, F., Athès, V., and Trelea, I.C., 2017, Mechanistic modeling and equilibrium prediction of the reactive extraction of organic acids with amines: A comparative study of two complexation-solvation models using 3hydroxypropionic acid, Sep. Purif. Technol., 189, 475-487.

[13] Blaga, A.C., and Malutan, T., 2012, Selective separation of vitamin $\mathrm{C}$ by reactive extraction, $J$. Chem. Eng. Data, 57 (2), 431-435.

[14] Salmi, T., Wärn, J., Mikkola, J.P., and Rönnholm, M., 2005, Modelling and simulation of porous, reactive particles in liquids: Delignification of wood, Comput. Aided Chem. Eng., 20, 325-330.

[15] Bludworth, J., and Knopf, F.C., 1993, Reactive extraction of lignin from wood using supercritical ammonia-water mixtures, J. Supercrit. Fluids, 6 (4), 249-254.

[16] Constant, S., Basset, C., Dumas, C., Di Renzo, F., Robitzer, M., Barakat, A., and Quignard, F., 2015, Reactive organosolv lignin extraction from wheat straw: Influence of Lewis acid catalysts on structural and chemical properties of lignins, Ind. Crops Prod., 65, 180-189.

[17] Sulaiman, S., Aziz, A.R.A., and Aroua, M.K., 2013, Reactive extraction of solid coconut waste to produce biodiesel, J. Taiwan Inst. Chem. Eng., 44 (2), 233-238.
[18] Thakre, N., Datta, D., Prajapati, A.K., Chaudhari, P.K., and Pal, D., 2017, Reactive extraction of citric acid using different extractants: Equilibrium, kinetics and modeling, Chem. Biochem. Eng. Q., 31 (4), 437-446.

[19] Eda, S., Borra, A., Parthasarathy, R., Bankupalli, S., Bhargava, S., and Thella, P.K., 2018, Recovery of levulinic acid by reactive extraction using tri- $n$ octylamine in methyl isobutyl ketone: Equilibrium and thermodynamic studies and optimization using Taguchi multivariate approach, Sep. Purif. Technol., 197, 314-324.

[20] Bora, M.M., Ghosh, A.C., Dutta, N.N., and Mathur, R.K., 1997, Reactive extraction or 6-aminopenicillanic acid with aliquat-336: Equilibrium and kinetics, Can. J. Chem. Eng., 75 (3), 520-526.

[21] Zhao, X., Wu, R., and Liu, D., 2018, Evaluation of the mass transfer effects on delignification kinetics of atmospheric acetic acid fractionation of sugarcane bagasse with a shrinking-layer model, Bioresour. Technol., 261, 52-61.

[22] Hajiha, H., and Sain, M., 2015, "The use of sugarcane bagasse fibres as reinforcements in composites" in Biofiber Reinforcements in Composite Materials, Eds. Faruk, O., and Sain, M., Woodhead Publishing Company, Cambridge, 525-549.

[23] Hemmasi, A.H., Samariha, A., Tabei, A., Nemati, M., and Khakifirooz, A., 2011, Study of morphological and chemical composition of fibers from Iranian sugarcane bagasse, Am. Eurasian J. Agric. Environ. Sci., 11 (4), 478-481.

[24] Gil, M., Teruel, E., and Arauzo, I., 2014, Analysis of standard sieving method for milled biomass through image processing. Effects of particle shape and size for poplar and corn stover, Fuel, 116, 328340.

[25] Pirogov, B.Y., and Zelinskii, A.G., 2009, Mass transport and effective diffusion coefficient in the reduction of hydrogen ions from aqueous sulfuric acid solutions: Numerical modeling, Russ. J. Electrochem., 45 (3), 336-344.

[26] Li, W., You, L., Schaffler, M.B., and Wang, L., 2009, 
The dependency of solute diffusion on molecular weight and shape in intact bone, Bone, 45 (5), 10171023.

[27] Tolbert, A., Akinosho, H., Khunsupat, R., Naskar, A.K., and Ragauskas, A.J., 2014, Characterization and analysis of the molecular weight of lignin for biorefining studies, Biofuels, Bioprod. Biorefin., 8 (6), 836-856.

[28] Pianosi, F., Beven, K., Freer, J., Hall, J.W., Rougier, J., Stephenson, D.B., and Wagener, T., 2016, Sensitivity analysis of environmental models: A systematic review with practical workflow, Environ. Modell.
Software, 79, 214-232.

[29] Nan, H.S., Dias, M.M., Lopes, J.C.B., and Rodrigues, A.E., 1996, Diffusion, convection and reaction in catalyst particles: Analogy between slab and cylinder geometries, Chem. Eng. J., 61 (2), 113-122.

[30] Fogler, H.S., 2016, Elements of Chemical Reaction Engineering, $5^{\text {th }}$ Ed., Prentice Hall, New Jersey.

[31] Crank, J., 1975, The Mathematics of Diffusion, $2^{\text {nd }}$ Ed., Clarendon Press, Oxford.

[32] Cussler, E.L., 2009, Diffusion: Mass Transfer in Fluid Systems, $3^{\text {rd }}$ Ed., Cambridge University Press, Cambridge. 